\title{
"Lar Doce Lar": Apego ao Lugar em Área de Risco diante de Desastres Naturais
}

\author{
Roberta Borghetti Alves \\ Ariane Kuhnen \\ Márcia Battiston \\ Universidade Federal Santa Catarina \\ Florianópolis, SC, Brasil
}

\begin{abstract}
RESUMO
O objetivo dessa pesquisa foi compreender as características do apego à moradia localizada em área de risco. A natureza do trabalho foi qualitativa com abordagem multimétodos, por meio do Walk-around-the-block e entrevista semiestruturada com 18 pessoas residentes em área avaliada pela Defesa Civil como de risco muito alto para inundações e deslizamentos. As falas foram analisadas por meio da Grounded Theory onde estabeleceu-se categorias de análise. Evidenciou-se que o processo funcional e o simbólico do apego ao lugar contribuíram para a manutenção deste fenômeno e para a permanência na casa. Em contrapartida, a ocorrência do desastre natural e os decorrentes sentimentos de insegurança e medo juntamente com as características físicas da moradia influenciaram no apego e no cuidado do ambiente de modo que houve uma ambivalência de sentimentos entre os participantes, repercutindo no anseio entre o partir e o permanecer na casa.
\end{abstract}

Palavras-chave: Psicologia Ambiental; Apego ao lugar; Casa; Área de Risco; Desastres Naturais.

\section{ABSTRACT}

\section{"Home Sweet Home": Place Attachment in Risk Area Facing Natural Disasters}

The goal of this research was to comprehend the characteristics of the attachment to a home located in a risk area. The structure of the paper was qualitative with a multimethod approach, through the Walk-around-the-block and semi-structured interview with 18 residents of an area evaluated by the Civil Defense (natural disasters management department) as having very high risk of flooding and landslides. The speeches were analyzed through Grounded Theory, from which analysis categories were established. It was evidenced that the functional and symbolic processes of the place attachment contributed to the maintenance of the phenomenon and to the staying in the house. On the other hand, the feelings of unsafety and fear arising from the occurrence of the natural disasters along with the physical characteristics of the home had influence upon attachment and care for the environment, in such way that there was an ambivalence of feelings among participants, resulting in distress between leaving or staying in the house.

Keywords: Environmental Psychology; Place Attachment; House; Risk Area; Natural Disasters.

\section{RESUMEN}

\section{"Holgar, Dulce Holgar": Apego al Lugar en Area de Riesgo delante de Desastres Naturales}

El objetivo de esta pesquisa fue comprender las características del apego a las viviendas situadas en areas de riesgo. El trabajo fue de naturaleza cualitativa con abordaje multimetodo, por medio del Walk-around-the-block y entrevista semiestructurada con 18 personas residentes de una area evaluada por la Defensa-Civil como de riesgo muy alto de inundación y deslizamientos. Las entrevistas fueron analizadas por medio de la Grounded Theory donde se establecieron categorías de análisis. Se evidenció que el proceso funcional y simbólico del apego al lugar contribuyó para la manutención de este fenómeno y para la permanencia en las casas. Por otro lado, la ocurrencia de los desastres naturales y los sentimientos recurrentes de inseguridad y miedo juntamente con las características físicas de la vivienda influenciaron el apego y el cuidado con el ambiente de modo que hubo una ambivalencia de sentimientos entre los participantes, repercutiendo en la ansiedad entre el partir y el permanecer en casa.

Palabras clave: Psicología Ambiental; Apego al Lugar; Casa; Area de Riesgo; Desastres Naturales. 


\section{INTRODUÇÃO}

Os desastres naturais ocasionam diversos impactos, seja sob o aspecto dos danos físicos e sociais (ausência das políticas públicas com vistas as questões sociais) seja pelos danos psicológicos diante das perdas vivenciadas (Alves, Lacerda, \& Legal, 2012). No Relatório Anual de Desastres do ano de 2012, o Brasil foi considerado pelo Center for Research on the Epidemiology of Disasters - CRED como um dos 10 países que mais tiveram danos devido a ocorrência de desastres naturais, sejam eles inundações, movimentos de massa ou secas (Sapir, Hoyois, \& Below, 2013). Além desses problemas ambientais, destaca-se a crescente ocupação de áreas irregulares, o que coloca a população em situação de risco, tornando-a vulnerável aos desastres (Centro Universitário de Estudos e Pesquisas sobre Desastres, 2010).

Neste panorama, profissionais que atuam nesta área (bombeiros, Defesa Civil, etc.) deparam-se com pessoas que residem em área de risco e que, mesmo quando notificadas pelos órgãos competentes a desocupar suas residências, permanecem neste local, muitas vezes, devido ao apego a este lugar (Centro Universitário de Estudos e Pesquisas sobre Desastres, 2010). Esse apego atribuído ao lugar é fenômeno de estudos na Psicologia Ambiental (PA), subdisciplina que estuda a pessoa em seu contexto, tendo como enfoque as interrelações entre a pessoa e o meio ambiente (Moser, 1998).

Em revisão na literatura sobre o apego ao lugar, Giuliani (2004) destaca três processos diferentes que podem resultar em apego e ser complementares quanto a sua ocorrência. Possuem características específicas, principalmente no que tange a estabilidade do apego $\mathrm{e}$, consequentemente, as ações voltadas à mudança de um local para o outro. Esses processos podem criar componentes distintos e atuar em conjunto a fim de formarem laços de apego ao lugar, derivando em (a) apego funcional, (b) apego simbólico e (c) apego resultante de um processo temporal e de familiaridade com o local.

No processo funcional, o apego ao lugar se dá em razão da quantidade e importância das necessidades que podem ser satisfeitas nesse lugar, fornecendo recursos e condições que deem suporte para o alcance dos objetivos específicos ou atividades desejadas (Williams $\&$ Vaske, 2003). Ele é resultado de uma relação pessoaambiente que possibilita um julgamento positivo do local frente às necessidades da pessoa, sendo uma característica mais cognitiva do que emocional. A estabilidade do apego depende mais das alternativas disponíveis no lugar, do que da qualidade deste lugar (Giuliani, 2004).
No processo simbólico são considerados os significados atribuídos pelas pessoas aos lugares, os quais são de origem individual e sociocultural que atuam como intermediários na relação pessoaambiente (Scannell \& Gifford, 2010). Este processo se dá por meio da importância simbólica de um lugar, como um repositório de emoções e relacionamentos que dão sentido e propósito para a vida das pessoas que o utilizam. O tempo de vinculação, nesse caso, não é relevante e a estabilidade do laço afetivo depende da relação entre o significado atribuído ao lugar e os elementos significativos para a identidade no momento da vinculação (Morgan, 2010; Giuliani, 2004).

O processo temporal deriva de um longo período de proximidade com o lugar. A principal característica desse processo de apego é o vínculo afetivo positivo entre uma pessoa e um lugar; mais especificamente, uma forte tendência de a pessoa manter a proximidade com tal lugar (Hidalgo \& Hernandez, 2001). Sua característica, por isso, é mais emocional que cognitiva, implicando no sofrimento pela separação e na dificuldade de substituição de um laço afetivo por outro (Giuliani, 2004), contribuindo para o desenvolvimento da identidade individual e comunitária.

No estudo ora apresentado foi considerado como lugar a moradia de risco, ou seja, a casa que está localizada em uma área considerada de risco pela Defesa Civil. A moradia tem sido referida na literatura como um dos lugares mais apreciados pelas pessoas, por propiciar meios que contribuem para a regulação emocional e para a reflexão acerca da identidade (Elali \& Medeiros, 2011), além de estarem relacionadas a ideia de conforto, segurança e tranquilidade (Santos, 2007). As investigações sobre o tema indicam como foco as relações entre as características físico-espaciais do lugar e os significados afetivos a ele atribuídos (Giuliani, 2004).

Com base no que foi supracitado acerca do apego à moradia em área de risco, foi realizada uma busca em bases de dados ${ }^{1}$ a fim de identificar a produção científica a cerca do tema, nas quais foram encontrados três artigos disponíveis. Wright e Storr (2009) pesquisaram o apego ao lugar, a dependência e a identidade em pessoas que reconstruíram suas casas após a ocorrência, em 2005, do furacão Katrina. Os resultados apontaram altos níveis de apego ao lugar, identidade e dependência. Os autores salientam que após a

\footnotetext{
As bases pesquisadas foram: Bireme, Pepsic, IndexPsi, Science Directe Redalyc. Utilizou-se como descritores "apego ao lugar (place attachment/ apego al lugar)" e "área de risco (risk area/área de riesgo)" ou "apego ao lugar (place attachment/apego al lugar)" e "desastres naturais (natural disasters/desastres naturales)", no mês de julho de 2014.
} 
ocorrência do furacão, os moradores tornaram-se mais conscientes do seu apego, identidade e dependência do lugar que residem. Esses aspectos colaboraram para o retorno dos participantes à moradia localizada em área de risco.

Já na pesquisa realizada por Carroll, Morbey, Balogh e Araoz (2009) foram analisados os impactos (de saúde e sociais) que as vítimas tiveram após a ocorrência da inundação em 2005, na cidade de Carlisle-Inglaterra. Os resultados apontaram que após a ocorrência do desastre natural os laços afetivos, bem como o sentimento de familiaridade com o lugar, foram negativamente afetados, uma vez que as casas foram destruídas devido à ocorrência do desastre natural. Corroborando com os autores supracitados, Willox, Harper, Ford, Landman, Houle e Borda (2012) pesquisaram a relação entre as mudanças climáticas e o apego ao lugar. Os resultados apontaram o apego ao lugar como um indicador vital da saúde e do bem-estar da população e a mudança climática como um fator negativo relacionado a este apego já que alteram as paisagens locais, refletindo em um impacto físico e emocional para a população.

Tais resultados evidenciam que a complexidade do contexto físico no qual as pessoas vivem e interagem influencia no apego ao lugar evidenciando a relevância do presente estudo pelas poucas pesquisas disponíveis nas bases de dados. Há um crescente interesse, tanto da ciência quanto dos órgãos públicos, para pesquisar e compreender esses fenômenos no intuito de embasar e subsidiar ações dos técnicos que atuam nessas áreas, criar estratégias e políticas públicas para reduzir os impactos causados pelos desastres naturais, bem como auxiliar a população que reside em área de risco e é removida de sua moradia. Com base nestas reflexões, este estudo teve como objetivo principal compreender as características do apego à moradia localizada em área de risco na perspectiva de seus moradores.

\section{MÉTODO}

A seguir, são abordados os aspectos referentes ao método proposto para a investigação descrevendo o delineamento da pesquisa, os instrumentos e os procedimentos da coleta de dados, o ambiente em que ocorreu a pesquisa, os participantes e a análise dos dados.

\section{Delineamento da pesquisa}

Esta pesquisa de natureza qualitativa caracterizase como um estudo exploratório descritivo, o qual teve um corte transversal, onde os dados informaram a situação no momento em que foi realizada a coleta dos dados (Sampiere, Collado, \& Lucio, 2006). Foi utilizada a abordagem multimétodos para coletar os dados. Essa abordagem articula diferentes técnicas de pesquisa que possibilitam uma averiguação mais precisa da multiplicidade do fenômeno (Gunther, Elali, \& Pinheiro, 2004).

\section{Instrumentos e procedimentos da coleta de dados}

A utilização de diferentes métodos para coleta dos dados possibilitou descrever a dinâmica relacional entre a pessoa e o ambiente, de modo que proporcionou a obtenção de uma perspectiva ampla do fenômeno pesquisado (Günther, Elali, \& Pinheiro, 2004). Foram utilizados instrumentos que contribuíram para compreender o ambiente da pesquisa (moradia em área de risco - método centrado no ambiente), e os sujeitos que residem nesse lugar (método centrado na pessoa).

Na primeira etapa do estudo foram identificadas as áreas de risco do município em estudo e os diferentes níveis (muito alto, alto, médio e baixo) aos quais estas áreas pertenciam, segundo a avaliação da Defesa Civil. Após essa identificação, foram selecionados, em conjunto com este Órgão, os moradores residentes nas áreas consideradas de risco muito alto para inundações e deslizamentos, com o objetivo de manter a homogeneidade do nível de risco das moradias pesquisadas. Para isso utilizou-se o mapa da cidade e o mapeamento dos bairros já realizados por este órgão. Selecionadas as áreas de muito alto risco realizou-se o Walk-around-the-block ("caminhada pelo local") onde estabeleceu-se o contato inicial com o local em estudo por meio da visita (Lynch \& Rivlin, 1970).

Nessa visita domiciliar buscou-se o contato com os possíveis participantes da pesquisa, a fim de explicar os objetivos da mesma e buscar a autorização destes por meio do Termo de Consentimento Livre e Esclarecido (TCLE). Com o consentimento dos participantes, realizou-se a entrevista semiestruturada, que foi gravada em áudio com o objetivo de capturar a linguagem precisa da narrativa. A entrevista buscou explorar as características demográficas dos participantes (sexo, idade, escolaridade etc), o ambiente da pesquisa contendo perguntas voltadas a situação da residência (casa própria, alugada ou emprestada), o tipo de casa (madeira, alvenaria ou mista), existência de saneamento básico, motivo que levou a residir neste local, etc.

Também investigou-se o apego ao lugar, por meio de perguntas relacionadas aos três processos que 
podem resultar em apego. Sobre o processo funcional as perguntas buscavam identificar as satisfações das necessidades relacionadas à moradia, como gastos com os danos, proximidade de bens de consumo, do trabalho ou da escola, dificuldades e facilidades em residir nesse local dentre outras. Referente ao processo simbólico, as questões foram voltadas aos significados atribuídos a casa e ao entorno, como a avaliação de morar nesse local/residência, satisfação com a casa, fatores de permanência, etc. Para o processo temporal buscouse identificar além do tempo de moradia nesse local, quais as relações com a comunidade e os principais fatores de permanência. Além disso, perguntou-se acerca do histórico relacionado aos desastres naturais nesse local, os impactos físicos e estruturais da casa, após o desastre, etc.

\section{Ambiente da pesquisa}

A pesquisa ocorreu em uma cidade localizada na Região do Vale do Itajaí em Santa Catarina que consta com aproximadamente 183.373 habitantes (Instituto Brasileiro de Geografia e Estatística, 2010). Em 2008, a cidade teve um dos eventos climáticos mais extremos. A concentração de chuva em poucos dias, antecedida de um período longo de precipitações, provocou a ocorrência de inundações, movimentos de massa e enchente na Bacia do Rio Itajaí. Além deste desastre, a cidade também foi atingida por uma inundação em 2011 e uma enxurrada (inundação brusca) em 2013. Ela é caracterizada, em sua maior parte, por vales de forma côncava, o que predispõe a ocorrência de inundações e deslizamentos de terra. Há ocupações em área de risco caracterizada pela ausência de mata ciliar, poluição por pesticidas, desmatamento e urbanização em encostas e morros (Dias, 2010).

\section{Participantes}

Para a seleção dos participantes utilizou-se o critério de saturação, onde foi realizada a suspensão de novos participantes quando os dados obtidos passaram a apresentar redundância ou repetição, de modo que a inclusão de novos participantes não contribuiria significativamente para o aperfeiçoamento da reflexão teórica fundamentada nos dados que foram coletados (Denzin \& Lincoln, 2011). A meta inicial era realizar 12 entrevistas a fim de atender aos critérios internacionais propostos por Francis, Johnston, Robertson, Glidewell, Entwistle, Eccles e Grimshaw (2010) e Baker e Edwards (2012) para pesquisas qualitativas, onde por meio de evidências demonstradas pelos estudos desenvolvidos, constatou-se que, em amostras não probabilísticas, os dados começaram a ser delineados na sexta entrevista e a saturação teórica na $12^{\mathrm{a}}$ entrevista. No entanto, neste estudo a referida saturação foi atingida na $18^{\mathrm{a}}$ entrevista ocorrendo regularidades nas informações e a reincidência temática ao que foi proposto nos objetivos do presente estudo.

A escolha dos participantes foi intencional, composta por procedimento não probabilístico, uma vez que foram estabelecidos critérios de inclusão para os participantes: a) morar em uma área considerada de muito alto risco pela Defesa Civil; b) residir em uma moradia que já foi atingida por algum desastre natural característico da cidade (inundação ou deslizamento de terra); e c) possuir a idade mínima de 18 anos no momento da ocorrência do desastre natural, pois os sujeitos menores que esta referida idade poderiam estar sob a tutela legal dos pais, e não ter a autonomia e/ou independência (financeira) para decidirem o lugar para morar.

Dos 18 participantes que compuseram esta pesquisa, 16 eram do sexo feminino e dois do sexo masculino. Com relação à idade, a média foi de 41 anos e cinco meses. A maioria dos participantes possuía ensino fundamental incompleto $(\mathrm{n}=11)$, seguido de analfabeto $(\mathrm{n}=3)$, ensino fundamental completo $(n=2)$, ensino médio completo $(n=1)$ e incompleto $(n=1)$. Sobre o estado civil, onze participantes eram casados, quatro viúvos e três eram solteiros. No quesito renda familiar, a maioria dos participantes $(\mathrm{n}=10)$ ganhavam dois salários mínimos, seguidos de um salário $(\mathrm{n}=6)$, três $(\mathrm{n}=1)$ e quatro salários $(\mathrm{n}=1)$. Ressalta-se que a maioria dos participantes $(n=10)$ reside na casa no máximo há cinco anos e possuem três filhos.

\section{Análise e discussão dos dados}

A análise dos dados teve uma perspectiva qualitativa e foi realizada por meio da Grounded Theory (teoria fundamentada empiricamente) de Strauss e Corbin (2008). Esta análise consistiu no estabelecimento de categorias, subcategorias e elementos de análise, após o processo de codificação dos dados, o qual foi realizado com auxílio do software Atlas/Ti $5.0^{\circledR}$.

A análise foi realizada seguindo uma sequência de passos e regras recomendados por Strauss e Corbin (2008): a) imersão nos dados coletados através de sistemáticas leituras das transcrições das entrevistas; b) codificação aberta dos dados, para posteriormente conceituá-los e categorizá-los por meio da análise das similaridades e diferenciações; c) nomeação das categorias de análise, caracterizada pelo processo de identificação de pontos nodais cuja similaridade possibilitou serem agrupados; d) codificação axial, a qual consistiu na relação entre os dados, proporcio- 
nando as categorias, as subcategorias e os elementos de análise; e) integração final entre as categorias, buscando a compreensão do fenômeno estudado, sendo consideradas as singularidades dos significados e julgamentos voltados ao apego à moradia de risco.

\section{RESULTADOS E DISCUSSÃO}

A compreensão das características do apego à moradia localizada em área de risco permeia a análise da relação pessoa-ambiente nesses lugares. A análise foi dividida em três partes que contemplam a caracterização do ambiente, dos participantes e das categorias, subcategorias e elementos de análise. Neste artigo foram debatidos os principais resultados provenientes do ambiente físico da pesquisa e das duas principais categorias de análise.

\section{Ambiente da pesquisa}

$\mathrm{O}$ ambiente de pesquisa caracteriza-se como de muito alto risco para a ocorrência de desastres naturais, de acordo com a definição da Defesa Civil. Houve evidências de instabilidade do solo, observadas pelos danos as moradias, como por exemplo, os danos visíveis na estrutura das casas com rachaduras e espaços entre as tábuas que constituem as paredes, desníveis entre os diferentes ambientes das casas além das cicatrizes de deslizamentos de modo a tornar difícil para a Defesa Civil monitorar a evolução deste processo, dado seu elevado estágio de desenvolvimento. É muito provável a ocorrência de desastre natural nesta área durante episódios de chuvas intensas e prolongadas, no período compreendido por uma estação chuvosa (Defesa Civil, 2013).

A posse dos terrenos é feita por usucapião, tornando difícil o processo de remoção. As ruas se caracterizam como de chão batido (apenas algumas são calçadas), com animais soltos pelas ruas e presença de muitos insetos, facilitando a disseminação de doenças. Além destes riscos, há ausência de saneamento básico nestas áreas, a qual é demonstrada pela falta de tratamento de esgoto e pela destinação deste diretamente no solo ou nos rios. Há habitações invadindo parcialmente o leito do rio, com fundações em forma de estacas. Os serviços de água e eletricidade, muitas vezes, são clandestinos, de modo que alguns moradores fazem sua própria fiação elétrica, ligando a luz da sua casa diretamente ao poste, correndo o risco da ocorrência de incêndio, além de não receberem a conta de luz. O lixo é jogado nas ruas e no rio, demonstrando a ausência de cuidado para com o meio ambiente, o qual pode contribuir para o aumento de insetos, ratos, baratas e outros agentes que disseminam doenças, bem como prejudicam o escoamento da água principalmente na ocorrência de inundação.

O material utilizado para a construção das casas é de madeira $(n=15)$, seguido de construções mistas $(n=2)$ e alvenaria $(n=1)$. Destaca-se os cortes em altas declividades do terreno, o que corrobora para a ocorrência dos movimentos de massa. Todas as moradias nessa pesquisa tinham ao menos um cômodo que foi destruído pela inundação. Elas localizam-se em áreas de invasão, sendo proibida a ocupação, de modo que os moradores não tinham a escritura da casa e não pagavam impostos a Prefeitura do município. A invasão dos moradores nesta área acarretou em consequências como a diminuição dos espaços verdes e a ameaça ao ecossistema local.

Nesta cidade as áreas de risco são caracterizadas pela ocupação de encostas $(n=8)$ ou próximo ao rio $(n=10)$, o que vai ao encontro dos resultados salientados por Pisani (2004), indicando que as ações humanas presentes nos processos de ocupação sem planejamento e a ausência de projetos apropriados para a construção das moradias são os principais fatores que contribuem para a ocorrência das inundações e de seus impactos. Dentre as ações, o autor destaca: a retirada da vegetação e a impermeabilização do solo; a modificação na topografia original do rio, podendo ocasionar estreitamento do leito do rio; presença de material sólido jogado no rio e transportado pelo curso d'água (esgoto sanitário, entulho de obras, lixo, etc); habitações que invadem o leito do rio por meio de fundações em forma de estacas e trechos de ampliações das casas sobre pequenos aterros, dentre outros.

Com base nestes resultados nota-se que a relação destes moradores com a sua moradia caracteriza-se como uma relação de satisfação das necessidades, uma vez que esse morador utiliza este ambiente em benefício próprio, ficando como secundárias as consequências que estas ações trarão para o ecossistema, principalmente no que tange ao impacto ambiental e como isso contribui para a ocorrência do desastre natural. Esses resultados serão corroborados na categoria voltada ao apego funcional, indicando uma relação de dependência com a moradia.

\section{Categorias de análise}

As categorias de análise discutidas são as que estão relacionadas aos processos funcional e simbólico do apego ao lugar, evidenciadas na fala dos moradores. No apego funcional obteve-se um conjunto de conhecimentos voltados ao julgamento e à avaliação do lugar frente às necessidades dos pesquisados, à disposição dos recursos e às condições da moradia para a realização das atividades desejadas pelos 
moradores e ao que fazem ou deixam de fazer para manter ou mudar este ambiente a fim de satisfazerem suas necessidades. No apego simbólico foram analisados os significados que os moradores trouxeram sobre a moradia, emergindo em resultados voltados ao sentimento de pertencimento ao lugar e ao esforço realizado para construir a casa própria. Em contrapartida, o processo temporal do apego não foi um componente que contribui para a ocorrência do fenômeno neste estudo.

\section{Categoria 01 - Apego funcional}

Nesta categoria buscou-se evidenciar as funcionalidades da moradia e como os moradores as percebem. Os participantes relatam que seu retorno à moradia após a ocorrência do desastre deu-se em virtude de não terem outro lugar próprio para residir. Deixam clara a importância que o fator econômico tem para suas vidas, de modo que não querem pagar aluguel. Esta é a principal característica que os atrai para residir em área de invasão. Além disso, não precisam pagar impostos e contas de luz e água, como visto no instrumento Caminhada ao local. Esses resultados corroboram com Rapoport (1985) que afirma que há sempre escolhas entre permanecer ou mudar de residência, mesmo que estas sejam consideradas difíceis, como não ter condições financeiras ou proibição de residir neste local, pois se a pessoa reside naquele lugar é porque algum aspecto deste ambiente lhe atraiu e, por algum motivo, este foi escolhido.

Identificou-se que algumas necessidades básicas foram supridas ao residir nesta moradia de risco, como, por exemplo, alimentar-se, descansar, ter privacidade, proteger-se da chuva, ter onde morar, ter um lugar para criar os filhos, não precisar pagar aluguel e não ter que morar na casa de parentes. Estes são fatores importantes que contribuem para o apego funcional, de modo a colocar o risco como secundário em suas vidas, demonstrando uma relação de dependência com o lugar. De acordo com Williams e Vaske (2003), a dependência reflete a importância de um lugar no fornecimento de recursos e condições que apoiam as atividades e metas desejadas pela pessoa. Quando as necessidades são satisfeitas, não há a emergência de mudança de lugar.

Em contrapartida com estes resultados, os participantes trouxeram sentimentos de tristeza, impotência, medo e insegurança frente à ocorrência do desastre natural e ao risco que correm, como pode ser percebido na fala de um dos entrevistados:

"Porque não tem sossego (...) quando chove é pior. A minha filha (...) está com começo de bronquite, de estar pegando chuva, vento, não é fácil, a outra minha filha também tem bronquite. Tirar do quentinho da cama, de madrugada, sair de baixo de chuva, não é fácil. Antes eu era apegada, mas agora desanimei de ficar aqui mesmo, por causa desses problemas mesmo, a gente não pode dormir sossegado, pois cada vez que vem a chuva, eu e meu marido ficamos acordados até de manhã. Nós não dormimos sossegados." (M09)

Estes sentimentos apareciam principalmente no período noturno, relembrando o desastre, demonstrando a inquietação a partir da ocorrência deste evento, de modo a interferir no sono e na tranquilidade, trazendo consequências como a diminuição da imunidade e, com isso, o aparecimento de doenças, como a bronquite e influenciando o apego. De acordo com Saile (1985), mesmo quando a interação com a moradia gera um sentimento de lar, este nem sempre reflete uma experiência positiva, pois pode trazer lembranças não tão prazerosas, como nesta pesquisa a experiência do desastre natural. Os resultados evidenciados por Martín, Hernández e Ruiz (2006) corroboram com os encontrados nessa pesquisa. Para os autores os ambientes que proporcionam risco e insegurança à população podem repercutir no desejo de mobilidade.

Nesse sentido, autores como Guiliani e Feldman (1993) salientam que ao falar de sentimentos negativos ou de insatisfação como possibilidades de relação afetiva com o lugar, pode significar contradição ao termo "afetividade". Porém os autores exemplificam dizendo que pessoas que participaram de guerras podem ter uma carga afetiva com o lugar, no entanto isto não representa que estes são apegados ao mesmo, pois a carga emocional pode ser gerada através de sentimentos negativos, como medo, tristeza, angústia, etc. Situações extremas como guerras e desastres, podem trazer o rompimento do vínculo emocional, gerando insatisfação e necessidade de mudança do lugar, como ocorrido com cinco participantes da pesquisa que saíram de sua moradia devido à ocorrência do desastre.

Os resultados dessa pesquisa evidenciam que a ocorrência do desastre natural influenciou o apego ao lugar dos participantes repercutindo sobre o processo funcional. Em tal processo a satisfação das necessidades econômicas foi a mais afetada devido à perda de bens (de partes da casa propriamente dita, bem como de móveis e utensílios) e com isso ter que ausentar-se do trabalho para reconstruir o que restou do desastre. Outra necessidade afetada foi a segurança. A ocorrência do desastre ocasionou sentimentos de medo e de insegurança, dificuldade para dormir e 
desassossego diante dos riscos. Este resultado também foi encontrado por Carroll et al. (2009) e Willox et al. (2012), cujas pesquisas com pessoas vítimas de desastres naturais apontaram que após o desastre, os laços afetivos, bem como o sentimento de familiaridade com o lugar, diminuíram, gerando sentimentos de insegurança e impotência, refletindo em impacto físico e emocional para a população.

Nesta pesquisa os moradores também contemplaram em suas falas as condições físicas e estruturais de suas moradias, referindo-se ao estado de conservação do imóvel, como pode ser exemplificado na fala da moradora M05. Destaca-se ainda, que a cada ocorrência de desastre, as condições estruturais deterioram-se ainda mais. Na caminhada pelo local da pesquisa percebeu-se que muitas casas são construídas pelos próprios moradores com madeira, o que contribui para terem um maior impacto do que as casas de alvenaria.

"Eu só vejo uma casa destruída. O que eu vejo hoje é isso. Eu fico olhando ao redor da minha casa, choro, mas eu me conformo, porque meus filhos me veem chorar e choram também. Eu relevo também. Agora com esse problema que a minha casa está caindo aos poucos. Já caiu para dentro, já caiu uma parte daqui." (M05)

Ao analisar as avaliações dos participantes, notase que eles tiveram mais julgamentos negativos do que positivos ao lugar em virtude do impacto que o desastre ocasionou na moradia. Ainda que em condições precárias, percebeu-se a busca por tornar esse espaço um lugar, dada a constante produção e apropriação deste pelos moradores, permitindo a eles imprimirem suas marcas, estabelecendo relações de poder e subsistência (Nogueira, 2009), seja por meio de arrumar a casa, reconstruí-la ou limpá-la. Além desta manutenção da moradia, os participantes da pesquisa salientam a busca pelo auxílio do governo municipal e outros, para saírem de sua moradia. Por esta área ser considerada de invasão, os programas existentes no município não contemplam estes moradores, pois não pagam impostos e consequentemente não têm a escritura da casa.

O único programa municipal que contempla essa população é o Aluguel Social. Isso ocorre em virtude da ocorrência do desastre e por residir em área de risco. Este programa é destinado às pessoas de baixa renda que tenham sua casa interditada pela Defesa Civil. O município contribui com até $\mathrm{R} \$$ 600,00 (seiscentos reais) durante um período de seis meses, desde que as pessoas saiam de sua moradia, como ocorreu com cinco participantes desta pesquisa. No entanto, após o término do programa, as pessoas terão que pagar aluguel, pois ao sair da moradia não podem mais retornar, uma vez que a casa pode já ter sido demolida ou outra pessoa já estar ocupando-a. Devido à realidade econômica desta população, onde a renda familiar gira em torno de um a dois salários mínimos, eles não conseguem esse feito e, por isso, optam por permanecer nesta moradia, não precisando pagar aluguel.

A espera dos moradores em receber auxílio de algum órgão público (Prefeitura, Defesa Civil ou Secretaria de Habitação) para melhorar a casa ou sair da mesma, evidencia a expectativa de serem assistidos, não percebendo sua corresponsabilidade pelo cuidado do entorno, como identificado na Caminhada pelo local, jogando lixo no chão ou no rio. Não obstante ao fato de não existirem programas específicos para esses moradores, uma vez que estão em área de invasão, a Secretaria de Habitação do município conta com um projeto que visa minimizar o aumento dessas áreas. O Projeto Vidas conta com o trabalho de profissionais que fiscalizam as áreas de invasão para não serem construídas mais casas e para que os moradores não alterem sua moradia atual, a fim de que não permaneçam por muito tempo nesse local. Assim, evidencia-se a complexidade da relação pessoa-ambiente, onde diversos atores (órgãos públicos, Defesa Civil e moradores) interagem na busca de elementos que permitam ampliar as discussões sobre a permanência ou não na moradia de risco.

A partir desta categoria obteve-se um conjunto de conhecimentos sobre as características e funcionalidades da moradia, indicando uma relação de dependência e satisfação das necessidades do morador para com sua moradia. De acordo com Giuliani (2004) a sociedade contemporânea está cada vez menos capaz de satisfazer a necessidade de ter apego ao lugar, movida pelo capitalismo e pela globalização, tende a seguir uma lógica de mobilidade urbana, refletindo em uma relação funcional com o lugar.

\section{Categoria 2 - Apego simbólico}

Esta categoria foi construída com base na importância simbólica dada ao lugar pelos participantes. Tuan (1983) destaca que entre todos os lugares de convivência humana, os ambientes residenciais são únicos, singulares e demasiadamente ricos. Dotar de valor tais ambientes é atribuir um significado a esse espaço. Essa atribuição de significados caracteriza-se como um dos processos do apego ao lugar (Giuliani, 2004).

As falas dos participantes demonstraram que o espaço tornou-se um lugar, devido ao tratamento afetivo dado a este e a possibilidade de acomodar-se. 
Segundo Tuan (1983), o espaço transforma-se em lugar uma vez que é reconhecido e dotado de valor pelos que ali residem. Os moradores pesquisados puderam ter um lar e não necessitar residir na rua. As narrativas trouxeram o simbolismo de ter seu próprio lugar, de modo a sentirem-se livres e independentes de seus familiares, sendo um lugar que podem chamar de "seu", conforme exemplificado na fala do morador M01.

"Eu sempre morei de favor na casa dos outros. Eu toda vida tive o sonho de ter o meu cantinho, e eu conquistei o meu cantinho, então, foi um sonho que se realizou, comprar minhas coisinhas, algumas até foram ganhas, mas foi um sonho que se realizou." (M01)

As narrativas denotaram também a oportunidade que tiveram de ter a casa própria, principalmente por ser algo tão esperado que conseguiram alcançar. Nesta relação pessoa-ambiente, a moradia contribuiu para a identidade da pessoa e para o crescimento pessoal. Segundo Giuliani (2004) a estabilidade do apego está relacionada neste processo com a ligação do significado do lugar e os elementos importantes para a identidade do indivíduo, como no estudo, ao obter a casa própria. Além disso, trouxeram à tona o esforço físico, mental e financeiro que fizeram para ter um lar. Dois participantes revelaram que construíram a casa com suas próprias mãos. Para eles, cada tábua que pregaram teve valor, sendo difícil renunciar a todo este simbolismo para ter outra casa, como é destacado pelo morador M12.

\section{"Olha, significa bastante, essa casa aqui foi suada, não só financeiramente, cada tábua dessa parede aqui foi eи е о meu marido que pregamos. (...) Essa casa foi construída pelas nossas mãos. (...) O fato de você conseguir comprar a tua casa, já é uma vitória. Agora você fazer a tua casa que nem a gente fez, construindo tábua por tábua. Vinha final de semana, vinha de noite trabalhar aqui pra acabar logo a nossa casinha, é, não tem o que dizer." (M12).}

As falas dos participantes evidenciaram a oportunidade de ter um lar e não apenas uma casa, como destaca Dovey (1985) ao conceituar casa e lar. Para o autor, e também como pôde ser observado nesse estudo, enquanto a casa é mais bem caracterizada como um objeto, uma parte de um ambiente, o lar pode ser entendido como um lugar, investido emocionalmente e um tipo de relação entre as pessoas e o ambiente, relações significativas entre os moradores e suas moradias. Contribuem na regulação emocional, definição e qualificação da identidade pessoal de quem faz uso deste lugar. Estes aspectos simbólicos contribuem para a permanência na moradia e para o retorno a ela mesmo após o desastre. A casa pode ser refeita, já a destruição do sonho é mais complexa e envolve mecanismos cognitivos que parecem manter dissociadas as questões que precisam de uma avaliação objetiva daquelas afetivas, de modo que esse lugar torna-se uma parte contribuinte para a constituição da identidade daqueles que o habitam.

\section{CONSIDERAÇÕES FINAIS}

Nesta pesquisa utilizou-se a abordagem multimétodos, que contribuiu para integrar e complementar os resultados, de modo que utilizou-se diferentes instrumentos para compreender as características do apego à moradia de risco. Adotou-se uma perspectiva qualitativa, o que permitiu dar voz e evidenciar o protagonismo dos participantes, possibilitando concluir que o apego ao lugar é um fenômeno complexo e que necessita de aprofundamento para sua compreensão, principalmente quando este lugar é uma área de risco para a população que nele reside.

O processo funcional de apego ao lugar foi o mais evidenciado pelos moradores em virtude da importância da satisfação de algumas necessidades, como ter um lugar para morar e não ter que pagar aluguel. Para os participantes, ter esta necessidade suprida é mais importante do que o risco que correm, demonstrando uma relação de dependência com o lugar. A questão econômica foi o fator que permeou as falas dos participantes, sendo identificado nesta pesquisa como um fator fundamental para a ocorrência do apego. Essa questão supera a insegurança e o medo e é um aspecto importante para a permanência na área de risco.

Já a insatisfação foi evidenciada nas falas dos moradores como um sentimento associado à ocorrência do desastre natural e ao risco de novas ocorrências, de modo a propiciar sentimentos opostos ao apego ao lugar, tais como insegurança e medo. Esses fatores, juntamente com as características e avaliações negativas do ambiente, como ausência de saneamento básico e danos ocorridos nas moradias, influenciaram o apego ao lugar e o cuidado com este local, repercutindo em uma ambivalência de sentimentos entre os participantes, emergindo o anseio entre o partir e o permanecer na casa. Tais resultados podem ser verificados pelas repercussões na vida dos participantes, sendo que quase um terço destes mudou após a realização da pesquisa.

No processo simbólico percebeu-se a importância da residência enquanto lar para os moradores entre- 
vistados, destacando-se valores relacionados com o pertencimento ao lugar e ao esforço dedicado à construção da moradia, sendo que para alguns participantes, esta foi a primeira casa própria. Esses apontamentos juntamente com a importância da satisfação das necessidades supracitadas, evidenciam o apego à moradia e fundamentam a permanência desses moradores em área de risco, de modo que o tempo de vinculação com o lugar tornou-se uma consequência do apego.

A carência de estudos no âmbito do apego ao lugar em situação de desastre natural torna a presente pesquisa um importante passo para a literatura na área da Psicologia Ambiental no intuito de compreender as características deste fenômeno, principalmente quando a moradia está localizada em uma área de risco. No entanto, salienta-se há necessidade de investigação de outros aspectos, como pesquisar o apego ao lugar em áreas com menor nível de risco e com moradias atingidas por outros tipos de desastres naturais, como a seca, para verificar as possíveis repercussões nesse fenômeno.

Salienta-se que a política municipal contempla apenas um programa habitacional para aqueles que residem nestas áreas, o chamado Aluguel Social que, contudo, não garante a casa própria. Para tanto, torna-se evidente a necessidade da criação de programas habitacionais em âmbito municipal, estadual e federal para que, a partir disso, seja pensada a retirada da população das áreas de risco. Caso contrário, os moradores irão permanecer nesse local, já que para eles é mais importante ter uma casa própria do que ficar pagando aluguel, de modo a colocar o risco como secundário em suas vidas.

\section{REFERÊNCIAS}

Alves, R. B., Lacerda, M. A. de C., \& Legal, E. J. (2012). A atuação do psicólogo diante dos desastres naturais: uma revisão. Psicologia em Estudo, 17(2), 307-315. http://dx.doi.org/10.1590/S1413-73722012000200014

Baker, S. E. \& Edwards, R. (2012). How many qualitative interviews is enough? Southampton: National Centre for Research Methods.

Carroll, B. Morbey, H. Balogh, R., \& Araoz, G. (2009). Flooded homes, broken bonds, the meaning of home, psychological processes and their impact on psychological health in a disaster. Health \& Place, 15, 540-547. http:// dx.doi.org/10.1016/j.healthplace.2008.08.009

Centro Universitário de Estudos e Pesquisas sobre Desastres. Universidade Federal de Santa Catarina. (2010). Gestão de Riscos e de Desastres: Contribuições da Psicologia. Florianópolis: CEPED.

Defesa Civil. (2013). Mapa de Indícios de Risco Geológico-Geotécnico Vila da Paz. Fonte: http://defesacivil.itajai. sc.gov.br/c/mapas

Denzin, N. K. \& Lincoln, Y. S. (2011). The sage handbook of qualitative research (4⿳亠丷⿵冂丶 ed.). Thousand Oaks: Sage Publications.

Dias, M. (2012). As chuvas de novembro de 2008 em Santa Catarina: um estudo de caso visando à melhoria do monitoramento e da previsão de eventos extremos. Fonte: http://www.ciram.com.br/GTC/downloads/NotaTecnica SC.pdf

Dovey, K. (1985). Home and homeless. In I. Altman \& C. M. Werner (Eds.). Home environments (pp. 33-64). New York: Plenum Press. http://dx.doi.org/10.1007/978-1-4899-2266-3_2

Elali, G. A. \& Medeiros, S. T. (2011). Apego ao lugar. In S. Cavalcante \& G. Elali, Temas Básicos em Psicologia Ambiental. Petrópolis: Vozes.

Francis, J., Johnston, M., Robertson, C., Glidewell, L., Entwistle, V., Eccles, M. P., \& Grimshaw, J. M. (2010). What is an adequate sample size? Operationalising data saturation for theory-based interview studies. Psychology \& Health, 25(10), 1229-1245. http://dx.doi.org/10.1080/08870440903194015

Giuliani, M. V. (2003). Theory of attachment and place attachment. In M. Bonnes, T. Lee, \& M. Bonaiuto, Psychological theories for environmental issues. Aldershot: Ashgate.

Giuliani, M. V. (2004). O lugar do apego nas relações pessoas-ambiente. In E. T. Tassara, E. P. Rabinovich, \& M. C. Guedes, Psicologia e ambiente (pp. 89-106). São Paulo: Educ.

Giuliani, M. \& Feldman, R. (1993). Place attachment in a developmental and cultural context. Jornal of Environmental Psychology, 13, 267-274. http://dx.doi.org/10.1016/S0272-4944(05)80179-3

Günther, H., Elali, G. A., \& Pinheiro, J. Q. (2004). A abordagem multimétodos em Estudos Pessoa-Ambiente: características, definições e implicações. Série: Textos de Psicologia Ambiental, 23. Brasília, DF: UnB, Laboratório de Psicologia Ambiental.

Hidalgo, M. C. \& Hernández, B. (2001). Place attachment: conceptual and empirical questions. Journal of Environmental Psychology, 21, 273-281. http://dx.doi.org/10.1006/jevp.2001.0221

Psico, Porto Alegre, v. 46, n. 2, pp. 155-164, abr.-jun. 2015 
Instituto Brasileiro de Geografia e Estatística (IBGE). (2010). Censo demográfico: resultados preliminares-Itajaí. Acesso em: 01 jul. 2012, disponível em: <http:/www.ibge.gov.br/cidadesat/painel/painel.php?codmun=420820>.

Martín, A., Hernández, B., \& Ruiz, C. (2006). Influencia de las condiciones ambientales e nel apego y la identidad conel bairro. In R. Martín, J. Berenger, \& J. A. Corraliza, Medio Ambiente, Bienestar Humano y Responsabilidad Ecológica. Espa-a: IX Congreso de Psicología Ambiental.

Moser, G. (1998). Psicologia Ambiental. Estudos de Psicologia, 3(1), 121-130. http://dx.doi.org/10.1590/S1413294X1998000100008

Nogueira, M. L. M. (2009). Subjetividade e Materialidade: cidade, espaço e trabalho. Fractal: Revista de Psicologia, 21(1), 69-86. http://dx.doi.org/10.1590/S1984-02922009000100006

Pisani, M. A. (2004). Inundações em áreas urbanas. Seminiário de Planejamento e Gestão Urbana: prevenindo desastres, Coordenadoria Estadual de Defesa Civil (CEDEC) e Centro Universitário Belas Artes de São Paulo, São Paulo.

Rapoport, A. (1985). Thinking about home environments: a conceptual framework. In I. Altman \& C. M. Werner, Home Environments. Advances in theory and research. New York: Plenum Press. http://dx.doi.org/10.1007/978-1-48992266-3 11

Saile, D. G. (1985). The Ritual Estabilishment of Home. In I. Altman \& C. M. Werner, Home Environments. New York: Plenum Press. http://dx.doi.org/10.1007/978-1-4899-2266-3_4

Sampiere, R., Collado, C. F., \& Lúcio, P. (2006). Metodologia de Pesquisa (3 ${ }^{\mathrm{a}}$ ed.). São Paulo: McGraw-Hil.

Santos, M. C. O. (2007). A representação social da moradia. Estudos e Pesquisas em Psicologia, UERJ, 7(2), $336-341$.

Sapir, D. G., Hoyois, P., \& Below, R. (2013). Annual Disaster Statistical Review 2012. Centre for Research on the Epidemiology of Disasters (CRED). Institute of Health and Society (IRSS).Université Catholique de Louvain Brussels, Belgium.

Scannell, L. \& Gifford, R. (2010). Defining place attachment: A tripartite organizing framework. Journal of Environmental Psychology, 30, 1-10. http://dx.doi.org/10.1016/j.jenvp.2009.09.006

Strauss, A. \& Corbin, J. (2008). Pesquisa qualitativa. Porto Alegre: Artemed.

Tuan, Y. (1983). Espaço e lugar: a perspectiva da experiência. São Paulo: Difel.

Morgan, P. (2010). Towards a developmental theory of place attachment. Journal of Environmental Psychology, 30 , 11-22. http://dx.doi.org/10.1016/j.jenvp.2009.07.001

Williams, D. R. \& Vaske, J. J. (2003). The measurement of place attachment: validity and generalizability of a psychometric approach. Forest Science, 49, 830-840.

Willox, A. C., Harper, S. L., Ford, J. D., Landman, K., Houle, K., \& Edge, V. L. (2012). "From this place and of this place:" Climate change, sense of place, and health in Nunatsiavut, Canada. Social Science \& Medicine, 75(3), 538-547. http://dx.doi.org/10.1016/j.socscimed.2012.03.043

Wright, E. C. \& Storr, V. H. (2009). There's no place like new orleans: sense of place and community recovery in the ninth ward after hurricane Katrina. Journal of Urban Affairs, 31(5), 615-634. http://dx.doi.org/10.1111/j.14679906.2009.00479.x

\section{Autores:}

Roberta Borghetti Alves - Psicóloga. Doutoranda do Programa de Pós-Graduação em Psicologia pela Universidade Federal de Santa Catarina. Membro do Grupo de Pesquisa do Laboratório de Psicologia Ambiental (LAPAM). Membro da Comissão Nacional de Psicologia nas Emergências e Desastres pelo Conselho Federal de Psicologia

ARIANE KuHnen - Psicóloga. Doutora em Ciências Humanas. Professora do Departamento de Psicologia na Universidade Federal de Santa Catarina, onde coordena o Laboratório de Psicologia Ambiental (LAPAM).

MÁrcia BAtTiston - Psicóloga. Doutoranda do Programa de Pós-Graduação em Psicologia pela Universidade Federal de Santa Catarina.

Membro do Grupo de Pesquisa do Laboratório de Psicologia Ambiental (LAPAM).

Endereço para correspondência:

Roberta Borghetti Alves

Rua Antônio Broglio, 275 - Glória

CEP 95200-000 Vacaria, RS, Brasil

E-mail: rborghettialves@gmail.com

Recebido em: 20.06.14

Aceito em: 17.11 .14 